\title{
Risk factors for recurrence following pterygium surgery procedure
}

\author{
O. J. Omotoye ${ }^{1, *}$, I.A Ajayi², K.O Ajite ${ }^{3}$ \\ ${ }^{1-3}$ Consultant, Dept. of Ophthalmology, Ekiti State University Teaching Hospital Ado Ekiti Nigeria
}

*Corresponding Author: O J Omotoye

Email: layoshol@yahoo.com

\begin{abstract}
Recurrence the most common complication following pterygium excision represents a significant surgical problem.

Purpose: To determine the prevalence of pterygium procedure and to find out various risk factors responsible for pterygium recurrence following the procedure.

Materials and Methods: A cross-sectional study of records of all patients that had pterygium surgery with 5-Flurouracil (5FU) and pterygium surgery with conjunctival autograft obtained from eye clinic and theatre register from January 2010 to July 2017 . Information on demographic characteristics, diagnosis, laterality, pre and post-operative visual acuity, types of procedure done and presence of recurrence. Data obtained were recorded and analyzed using Statistical Package for Social Sciences (SPSS) version 25. Ethical approval was obtained from the institution's ethical review committee.

Results: Forty three (43) patients had pterygium surgery during this period. This constituted (2.9\%) of all ophthalmic surgeries done in this centre. There were 17(39.5\%) males and $26(60.5 \%)$ females. Recurrence following Pterygium procedure was slightly above a quarter of all the patients. The recurrence rate following conjunctival with autograft procedure was $2(10 \%)$ compared with $9(39.1 \%)$ with pterygium excision +5 FU. Risk factors for Pterygium recurrence following the procedure were found to be significantly higher among in-door workers than out-door workers; excision $+5 \mathrm{FU}$ than conjunctival autograft respectively.

Conclusion: Tthe modifiable risk factor identified for pterygium recurrence following pterygium surgery is safe and effective conjunctival autograft surgical technique. This should be meticulously approached in such a way as to minimize this post-operative complication.
\end{abstract}

Keywords: Pterygium, Procedure, Recurrence, Risk.

\section{Introduction}

Pterygium is a wing shaped conjunctival encroachment onto the cornea generally situated on the nasal side. ${ }^{1}$ It was reported that worldwide, pterygium prevalence varies from $2.8 \%$ to $23.7 \%$ in different population ${ }^{2-4}$ with factors such as outdoor working environment, aging, male sex, living in an area with higher exposure to ultraviolet radiation, dry and windy climate are associated with formation of pterygium. ${ }^{5,6}$ Surgery is the treatment of choice. Amongst the documented indications for surgical treatment are reduction in vision especially advanced pterygium that has covered the visual axis and cosmetic/unacceptable appearance of the eye. ${ }^{7}$ The recurrence rate of pterygium after excision is high (30$50 \%){ }^{8}$ The high recurrence rates are associated with different surgical techniques. ${ }^{1}$ Recurrence of pterygium is the most common complication after pterygium excision and recurrent pterygium represents a significant surgical problem. ${ }^{9}$ The theory of corneal limbal stem cell deficiency has been reported to be responsible for the high rates of recurrence. ${ }^{10}$ It was also reported that pterygium recurrence is due to surgical trauma and subsequent postoperative inflammation that activate proliferation of subconjunctival fibroblasts and vascular cells and deposition of proteins. ${ }^{11}$ There are different documented surgical methods to prevent pterygium recurrence: these include conjunctival autograft, limbal and limbal-conjunctival transplant, conjunctival flap and conjunctival rotation autograft surgery, amniotic membrane transplant, cultivated conjunctival transplant, lamellar keratoplasty, and the use of fibrin glue. ${ }^{12}$ Meanwhile autologous conjunctival grafting was reported to give both low recurrence rate and high safety. ${ }^{1}$ The seemly best method should be considered for all patients though this might not generally be feasible considering other confounding factors required for this technique. The study was to determine the prevalence of pterygium procedure and to find out various risk factors responsible for the pterygium recurrence following the procedure in other to minimize the rate of the surgical problem.

\section{Materials and Methods}

This was a cross-sectional study of records of all patients that had pterygium surgery with 5-Flurouracil $(5 \mathrm{FU})$ and pterygium surgery with conjunctival autograft obtained from eye clinic and theatre register from January 2010 to July 2017. Information on demographic characteristics, diagnosis, laterality, pre and post-operative visual acuity, types of procedure done and presence of recurrence. The patients were followed up till 6weeks postoperatively to detect any recurrence. Visual acuity was categorized with $\geq 6 / 18$ as normal, $<6 / 18$ to $>3 / 60$ as visual impairment and $<3 / 60$ as blindness. Ethical approval was obtained from the institution's ethical review committee though data collection did not directly involve patient's participation. Data obtained were recorded and analyzed using Statistical Package for Social Sciences (SPSS) version 25. Means (Standard deviations) were used to describe the distributions of continuous variables. Categorical variables were described in Percentages. Comparisons of categorical data were performed with the use of Pearson's chi-square test. $P<0.05$ was considered statistically significant.

\section{Results}

Forty three (43) patients had pterygium surgery during this period. This constituted $(2.9 \%)$ of all ophthalmic 
surgeries $(1,493)$ done in this centre. There were $17(39.5 \%)$ males and $26(60.5 \%)$ females with a male to female ratio of $1: 1.5$. The ages ranged from 12 years to 82 years with mean age of $52.97 \pm 14.36$ years. There were $23(53.5 \%)$ patients that had pterygium excision with application of 5-FU while $20(46.5 \%)$ had pterygium excision with conjunctiva autograft. All the cases were unilateral with $25(58.1 \%)$ performed in the right eye and $18(41.9 \%)$ in the left eye.

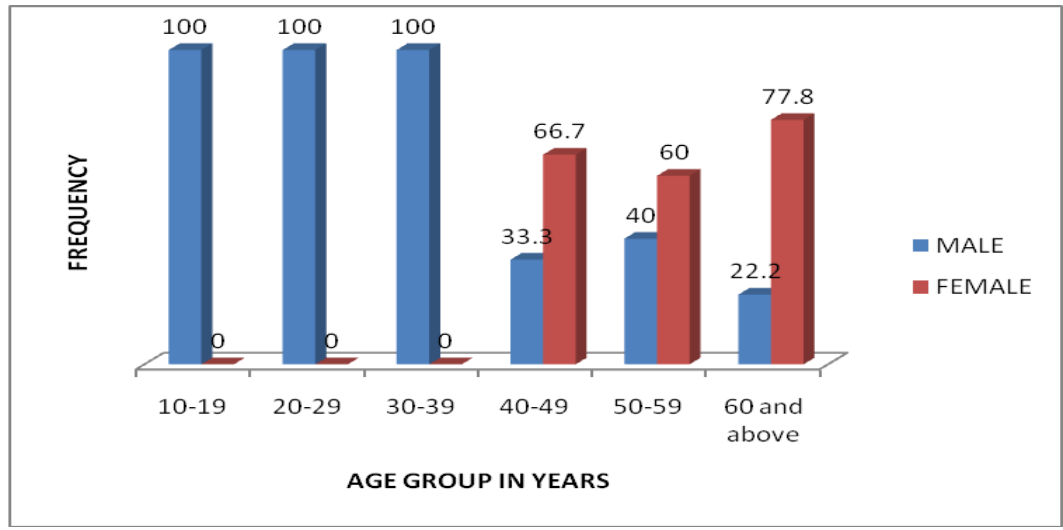

Fig. 1: Age and sex distribution

Pterygium procedure was predominantly done in males below 40years of age and in females 40 years and above in this study.

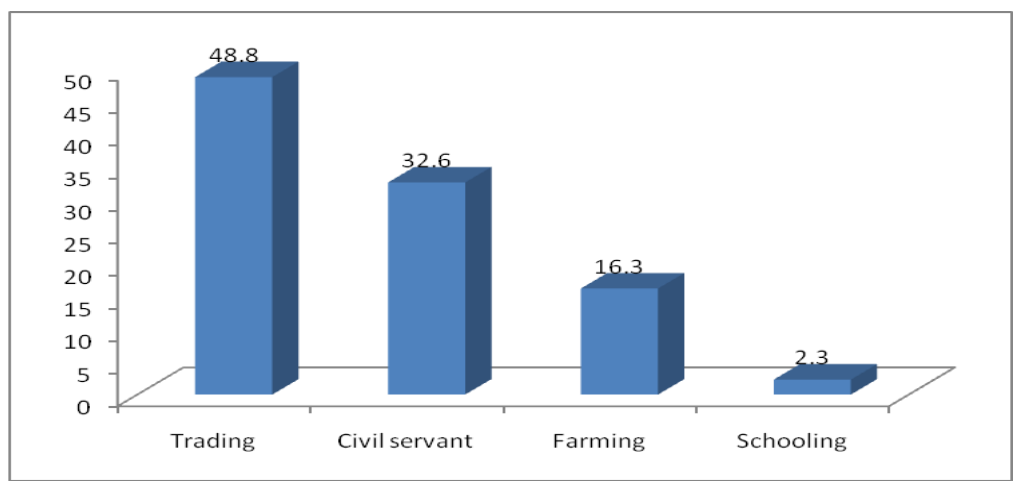

Fig. 2: Occupation of patients that had pterygium procedure

Almost half of the patients $21(48.8 \%)$ that had pterygium procedure were traders while the least was found among students.
Pterygium surgery was performed in $30(69.8 \%$ ) of outdoor workers compared with $13(30.2 \%)$ of in-door workers $(\chi 2=6.721, \mathrm{df}=1, \mathrm{p}=0.010)$.

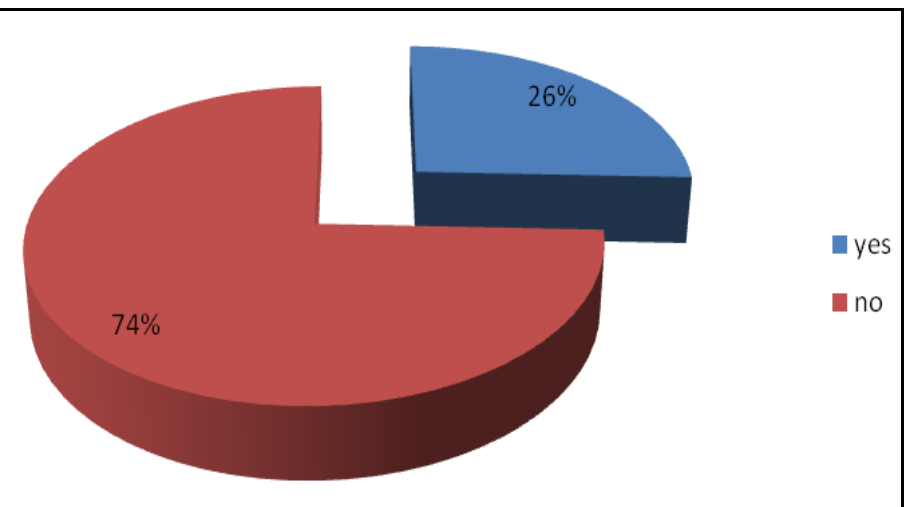

Fig. 3: Recurrence rate following surgery

Recurrence following Pterygium procedure was slightly above a quarter of all the patients that had Pterygium excision. $(\chi 2=10.256, \mathrm{df}=1, \mathrm{p}=0.001)$. 


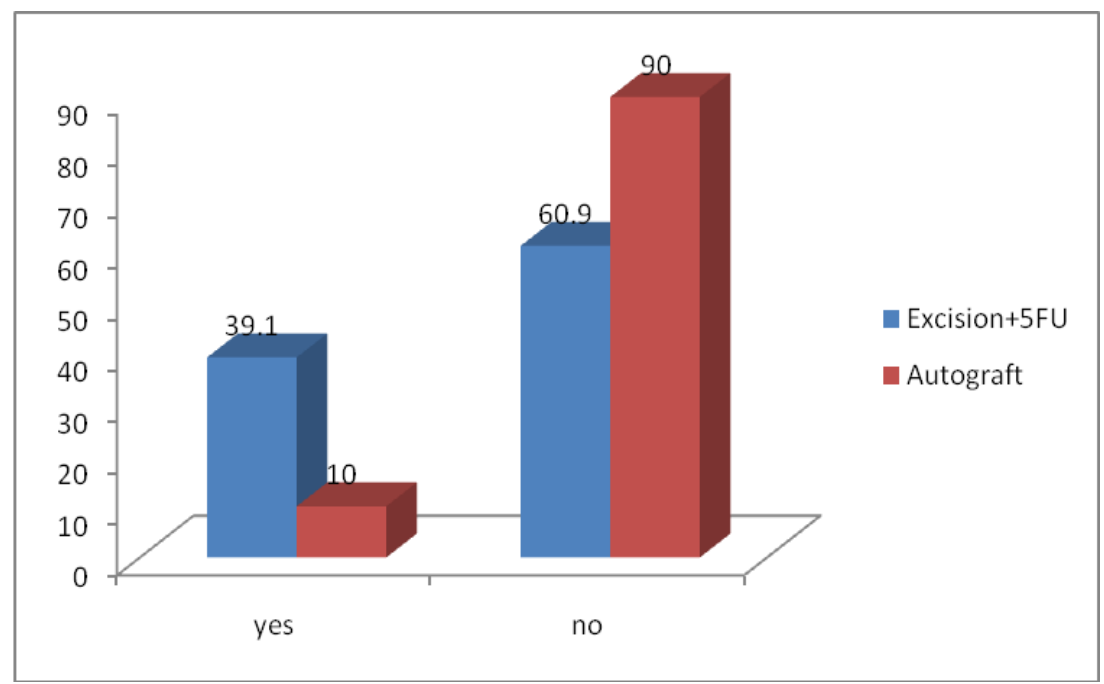

Fig. 4: Recurrence rate following conjunctival autograft compared with excision $+5 F U$

The recurrence rate following conjunctival with autograft procedure was $2(10 \%)$ compared with $9(39.1 \%)$ with pterygium excision $+5 \mathrm{FU}$. $(\chi 2=4.768, \mathrm{df}=1, \mathrm{p}=0.039$

Table 1: Risk factors for pterygium recurrence following surgery

\begin{tabular}{|l|c|c|c|c|}
\hline Variable & Recurrence & & \\
\hline & Yes n(\%) & No n(\%) & Total & P value \\
\hline Preoperative VA & $7(35.0)$ & $13(65.0)$ & 20 & \\
\hline$\geq 6 / 18$ & $4(17.4$ & $19(82.6)$ & 23 & .0295 \\
\hline$<6 / 18$ & $5(29.4)$ & $12(70.6)$ & 17 & \\
\hline Gender & $6(23.1)$ & $20(76.9)$ & 26 & 0.728 \\
\hline Male & $7(46.7)$ & $(53.3)$ & 15 & \\
\hline Female & $24(85.7)$ & 28 & 280.031 \\
\hline Occupation & $3(60.0)$ & 5 & \\
\hline In-door workers & $4(14.3)$ & $29(76.3)$ & 38 & 0.589 \\
\hline Out-door workers & $2(40.0)$ & $14(60.9)$ & 23 & \\
\hline Age & $9(23.7)$ & $18(90.0)$ & 20 & 0.039 \\
\hline$<40 y r s$
\end{tabular}

Risk factors for Pterygium recurrence following the procedure were found to be significantly higher among indoor workers than out-door workers; excision $+5 \mathrm{FU}$ than conjunctival autograft respectively.

\section{Discussion}

Pterygium procedure done was relatively low $(2.9 \%)$ compared to other ophthalmic procedures done in this centre. This is lower than the study in done in Singapore National Eye centre where pterygium surgery was the second most common ocular procedure after cataract surgery. ${ }^{13}$ However, the procedures were well indicated as most were either due to advanced presentation or cosmetically unacceptable eye appearance. The procedures were slightly performed more in females especially amongst aged 40 years above than in males. This is similar to a study done at National university hospital, Daegu South Korea. ${ }^{14}$ This might not be unconnected to cosmetically unacceptable eye appearance which is an important indication for the procedure. It has been documented that women are more concerned about their outward appearance thus more sensitive to the imposed cosmetic disfigurement arising from oculoplastic disorders. ${ }^{15}$ The mean age of over 50 years having pterygium procedure in this study is in line with the report that age increases the exposure to predictors such as ultraviolet light, outdoor working habit, dust particles which increase the precipitation of pterygium. ${ }^{16}$

Recurrence of pterygium following pterygium excision in this study was $26 \%$ this is slightly lower than reported findings in the literature where $33-45 \%$ was reported 
following a simple excision. ${ }^{17}$ This might be due to the fact almost half of the patients had conjunctival autograft procedure which has been documented to have a lower recurrence rate ${ }^{18}$ It has been reported in the literatures that transplantation of conjunctival forms a barrier to the proliferation and advancement of residual abnormal tissue towards the limbus therefore reducing recurrence. ${ }^{19}$ This study showed that the recurrence rate following conjunctival with autograft procedure was low compared with pterygium excision +5FU.This is similar to other studies. ${ }^{14,20}$ The risk factors identified from this study which were significantly associated with recurrence rate were occupation and the types of surgical procedure done. However, recurrence rate was significantly higher among indoor workers than outdoor workers in this study contrary to reports in the literature. ${ }^{13,16}$ No reason could be adduced for this finding. The expected result ought to be opposite since outdoor workers are exposed to predictors responsible for formation of pterygium ab initio. ${ }^{16}$ These outdoor workers can be educated to the use of protective goggles and wearing of hat to prevent exposure to dust particles and ultra violet rays of light which can precipitate pterygium recurrence. ${ }^{16}$ Most importantly, the choice of technique for the pterygium procedure should be seriously considered. Since conjunctival autograft with sutures is associated with low recurrence rate though with suture-related complications, ${ }^{21}$ this procedure is therefore recommended for most patients. Other risk factors though not statistically significant which influenced recurrence rate were pre-operative visual acuity, age and gender of the patients.

The modifiable risk factor for pterygium recurrence following surgery is the surgical technique which the surgeons must meticulously approach to reduce the complication as much as possible. The increase surgical time and financial implication can be overcome with benefit of low recurrence associated with conjunctival autograft procedure.

In conclusion, the modifiable risk factor identified for pterygium recurrence following pterygium surgery is the safe and effective conjunctival autograft surgical technique which must be meticulously approached in such a way as to minimize this post-operative complication. The outdoor workers should also be counselled on the use of protective wears from exposure to the protagonists of pterygium recurrence.

\section{Conflict of Interest: Nil.}

\section{References}

1. Koranyi G, Seregard S, Kopp E. Cut and paste: a no suture, small incision approach to pterygium surgery. $\mathrm{Br} J$ Ophthalmol. 2004;88(7):911-914.

2. McCarty CA, Fu CL, Taylor HR. Epidemiology of pterygium in Victoria, Australia. Br J Ophthalmol. 2000;84(3):289-292.

3. Bueno-Gimeno I, Montes-Mico R, Espana-Gregori E, Pons A. Epidemiologic study of pterygium in a Saharan population. Ann Ophthalmol. 2002;34(1):43-6.

4. Luthra R, Nemesure BB, Wu S-Y, Xie SH, Leske MC Frequency and risk factors for pterygium in the Barbados Eye Study. Arch Ophthalmol. 2001;119(12):1827-1832.
5. Shiroma H, Higa A, Sawaguchi S, Iwase A, Tomidokoro A, Amano S, et al. Prevalence and risk factors of pterygium in a southwestern island of Japan: the Kumejima Study. Am J Ophthalmol. 2009;148(5):766-771. e1.

6. Nangia V, Jonas JB, Nair D, Saini N, Nangia P, Panda-Jonas S. Prevalence and associated factors for pterygium in rural agrarian central India. The central India eye and medical study. PloS one. 2013;8(12):e82439.

7. Fasasi M, Azonobi I, Olatunji F, Saka E. Prevalence of pterygium in a tertiary hospital in North-Western Nigeria. $J$ Chitwan Med Coll. 2015;5(3):46-51.

8. Mahar P, Nwokora G. Role of mitomycin C in pterygium surgery. Br J Ophthalmol. 1993;77(7):433-435.

9. Yaisawang S, Piyapattanakorn P. Role of post-operative topical corticosteroids in recurrence rate after pterygium excision with conjunctival autograft. $J$ Med Assoc Thailand= Chotmaihet Thangphaet. 2003;86:S215-23.

10. Tseng SC, Lee S-B, Li D-Q. Limbal stem cell deficiency in the pathogenesis of pterygium. PTERYGIUM edited by Hugh R Taylor. 2000.

11. Ma DH-K, See L-C, Liau S-B, Tsai RJ-F. Amniotic membrane graft for primary pterygium: comparison with conjunctival autograft and topical mitomycin C treatment. Br J Ophthalmol. 2000;84(9):973-978.

12. Ang LP, Chua JL, Tan DT. Current concepts and techniques in pterygium treatment. Curr Opin Ophthalmol. 2007;18(4):308313.

13. Saw SM, Banerjee K, Tan D. Risk factors for the development of pterygium in Singapore: A hospital-based case-control study. Acta Ophthalmol Scand. 2000;78(2):216-220.

14. Kwon SH, Kim HK. Analysis of recurrence patterns following pterygium surgery with conjunctival autografts. Med. 2015;94(4).

15. Balogun BG, Adekoya BJ, Balogun MM, Ehikhamen OA. Orbito-oculoplastic diseases in lagos: a 4-year prospective study. Middle East Afr J Ophthalmol. 2014;21(3):236.

16. Anbesse DH, Kassa T, Kefyalew B, Tasew A, Atnie A, Desta B. Prevalence and associated factors of pterygium among adults living in Gondar city, Northwest Ethiopia. PloS one. 2017;12(3):e0174450.

17. Kawasaki S, Uno T, Shimamura I, Ohashi Y. Outcome of surgery for recurrent pterygium using intraoperative application of mitomycin $\mathrm{C}$ and amniotic membrane transplantation. Jap J Ophthalmol. 2003;47(6):625-626.

18. Chaidaroon W, Wattananikorn S. Conjunctival autograft transplantation for primary pterygium. J Med Assoc Thailand= Chotmaihet thangphaet. 2003;86(2):111-115.

19. Riordan-Eva P, Kielhorn I, Ficker L, Steele AM, Kirkness C. Conjunctival autografting in the surgical management of pterygium. Eye. 1993;7(5):634.

20. Kumar S, Singh R. Pterygium excision and conjunctival autograft: A comparative study of techniques. Oman J Ophthalmol. 2018;11(2):124.

21. Tan D. Conjunctival grafting for ocular surface disease. Curr Opin Ophthalmol. 1999;10(4):277-281.

How to cite this article: Omotoye O. J, Ajayi I.A, Ajite K.O. Risk factors for recurrence following pterygium surgery procedure. Int $\mathrm{J}$ Ocul Oncol Oculoplasty. 2018;4(4):159-162. 